\title{
Clinical Correlates of Hoarding With and Without Comorbid Obsessive-Compulsive Symptoms in a Community Pediatric Sample
}

\author{
Christie L. Burton, Jennifer Crosbie, Annie Dupuis, Carol A. \\ Mathews, Noam Soreni, Russell Schachar and Paul D. Arnold
}

Version Post-print/accepted manuscript

Citation Burton CL, Crosbie J, Dupuis A, Mathews CA, Soreni N, Schachar R, (published version) Arnold PD. Clinical correlates of hoarding with and without comorbid obsessive-compulsive symptoms in a community pediatric sample.

Journal of the American Academy of Child \& Adolescent Psychiatry. 2016 Feb 29;55(2):114-21.

Additional Publisher The published version of this article can be found at Information https://doi.org/10.1016/j.jaac.2015.11.014.

Copyright/License

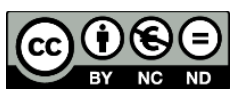

(C) 2016. This work is licensed under the Creative

Commons Attribution-NonCommercial-NoDerivatives 4.0 International License. To view a copy of this license, visit http://creativecommons.org/licenses/by-nc-nd/4.0/.

How to cite TSpace items

Always cite the published version, so the author(s) will receive recognition through services that track citation counts, e.g. Scopus. If you need to cite the page number of the author manuscript from TSpace because you cannot access the published version, then cite the TSpace version in addition to the published version using the permanent URI (handle) found on the record page.

This article was made openly accessible by $U$ of $T$ Faculty. Please tell us how this access benefits you. Your story matters. 
Hoarding in a Community Pediatric Sample

\section{Clinical Correlates of Hoarding with and without Comorbid Obsessive-Compulsive Symptoms in a Community Pediatric Sample}

Journal of the American Academy of Child and Adolescent Psychiatry (2016). 55(2), 114-121

Christie L. Burton‡, PhD*, Jennifer Crosbie, PhD, Annie Dupuis, PhD, Carol A. Mathews, MD, Noam Soreni, MD, Russell Schachar ${ }^{7}$ MD and Paul D. Arnold, MD, PhD

${ }^{1}$ Genetics \& Genome Biology, ${ }^{2}$ Psychiatry, ${ }^{3}$ Neurosciences \& Mental Health, ${ }^{4}$ Child and Evaluative Health Sciences: Hospital for Sick Children, Toronto, ON

${ }^{5}$ Psychiatry, ${ }^{6}$ Dalla School of Public Health, ${ }^{7}$ Institute of Medical Sciences: University of Toronto, Toronto, ON ${ }^{8}$ Psychiatry, Genetics Institute: University of Florida, Florida

${ }^{9}$ Psychiatry, St. Joseph's Healthcare: Hamilton, ON

10Psychiatry and Behavioural Neurosciences, Mc Master University: Hamilton, ON

${ }^{11}$ Mathison Centre for Mental Health Research and Education, The University of Calgary; Calgary, AB

\section{Corresponding Author*:}

Christie L. Burton, PhD

The Hospital for Sick Children (Genetics \& Genome Biology/Psychiatry)

555 University Ave, 4289B, Toronto, ON M5G 1X8

Phone: 416.813.7654 ex 302346/Fax: 416.813 .6565

Email: c.burton@utoronto.ca

Acknowledgements: CIHR operating grants awarded to PA (MOP-106573) and RS (MOP - 93696) and a CIHR fellowship for CLB supported this work. We thank Lauren Erdman, MSc (Hospital for Sick Children) for statistical support and everyone involved in collecting our dataset.

Financial Disclosures: RS consults for Highland Therapeutics, Purdue Pharma, and ehave and is the Toronto Dominion Bank Financial Group Chair in Child and Adolescence Psychiatry. CLB, JC, AD, CAM, NS and PAD report no biomedical financial interests or potential conflicts of interest.

Keywords: Hoarding, Obsessive-Compulsive Disorder, Attention-Deficit/Hyperactivity Disorder, Child and Adolescent, Community Sample

Article can be found at: http://dx.doi.org/10.1016/j.jaac.2015.11.014 


\begin{abstract}
Objective. We assessed the prevalence and clinical correlates of hoarding, with and without obsessive-compulsive (OC) symptoms, in a community-based pediatric sample. Methods. We measured hoarding and OC symptoms using the Toronto Obsessive-Compulsive Scale (TOCS) in 16718 youth aged 6-17 years in the community. We classified participants with high and low symptom counts for hoarding and OC into four groups: Hoarding+OC; Hoarding-only, OC-only and Control (no OC or hoarding symptoms). We compared these four groups on parent- or self-reported medical and psychiatric conditions, anxiety symptoms measured with the Child Behavior Checklist (CBCL) and attention-deficit/hyperactivity disorder (ADHD) symptoms measured with the Strengths and Weaknesses of Attention-Deficit/Hyperactivity Disorder Symptoms and Normal Behavior Scale (SWAN). Results. Almost 10\% of participants were in the high hoarding group. Of these participants, $40 \%$ did not fall into the high OC group. Prevalence of reported psychiatric disorders (e.g., ADHD, autism spectrum disorder, obsessive-compulsive disorder) was greater in the hoarding (Hoarding+OC and Hoarding-only) and OC groups (Hoarding+OC and OC-only) than the non-hoarding (OC-only and Control) and non-OC groups (Hoarding-only and Control). ADHD, specifically inattentive symptoms, were more common in the Hoarding-only than in the OC-only group, while anxiety symptoms were more common in the OC-only than in the Hoarding-only group. Conclusions. In a community pediatric sample, hoarding symptoms occurred in the presence and absence of obsessive-compulsive symptoms. Hoarding symptoms alone had some unique clinical correlates, in particular more inattentive ADHD and fewer anxiety symptoms. These findings suggest that hoarding is distinct from OC traits in youth.
\end{abstract}




\section{Introduction}

Pathological hoarding is characterized by difficulty discarding and excessive acquisition of seemingly useless items leading to clutter and impairment ${ }^{1,2}$. Hoarding disorder affects approximately $2-5 \%$ of adults ${ }^{3}$ and $2 \%$ of adolescents ${ }^{4}$. Although pathological hoarding is traditionally considered an adult disorder, most adults that hoard (70\%) report that their symptoms began before the age of 20 , with a median age of onset of $11-15$ years $^{5-7}$.

One unanswered question about hoarding is whether it is distinct from obsessivecompulsive disorder (OCD) in children. Pathological hoarding was a subtype of OCD in the Diagnostic and Statistical Manual of Mental Disorders $4^{\text {th }}$ edition - text revision (DSM-IV-TR) ${ }^{8}$. A new diagnostic category of hoarding disorder was created in the new edition of the DSM (DSM-59) because of findings that more than $80 \%$ of adults with pathological hoarding do not meet criteria for $\mathrm{OCD}^{10}$ and that hoarding in adults is impairing and neurobiologically distinct from OCD 11 . Some children with OCD also hoard (approximately 19-30\%12-14) but the existence, prevalence and correlates of hoarding symptoms outside the context of pediatric OCD is unclear ${ }^{12}$. A communitybased study would be useful to characterize hoarding in youth, especially in the absence of OCD, because community-based samples are less likely than clinical samples to have biased rates of comorbidity and severe illness ${ }^{15-17}$.

A second unanswered question about pediatric hoarding is whether its pattern of clinical correlates is independent or unique from pediatric OCD. We know $\mathrm{OCD}^{18}$ and possibly hoarding 10,13,19-24 are frequently comorbid with attention-deficit/hyperactivity disorder (ADHD) in children. However, we do not know how often hoarding appears, with or without ADHD, in the absence of OCD. We also do not know if hoarding differentially presents with inattentive or for hyperactiveimpulsive symptoms of ADHD 10,13,19,23-26. Understanding the relationship between ADHD and hoarding could be particularly useful because of their possible behavioral and cognitive overlap $19,22,24,27,28$ which, in turn, could inform new treatments and trajectories of affected 
individuals. Anxiety is also comorbid with hoarding ${ }^{10}$ and $\mathrm{OCD}^{29}$ but it is unclear whether hoarding presents with anxiety in the absence of OCD in children.

We investigated the prevalence and characteristics of hoarding and its comorbidity with obsessive-compulsive (OC) symptoms in youth from the community. Specifically, we asked if high hoarding symptoms presented in the absence of high OC symptoms in children and adolescents and if high hoarding and OC symptoms had common or different correlates, including ADHD symptoms. A finding that high hoarding symptoms occurs independently of high OC symptoms and with unique correlates in youth in the community would support the distinct DSM-5 category of hoarding not only for adults but for youth as well.

\section{Methods}

\section{Participants}

The sample has been described elsewhere ${ }^{30} .17263$ individuals aged 6-17 years were recruited to the Thoughts, Actions and Genes (TAG) project at the Ontario Science Centre in Toronto, Canada. Parents of children ages 6-15 or participants aged 13-17 provided consent, completed rating scales for OC, hoarding and ADHD traits, and responded to questions about history of medical/psychiatric conditions diagnosed in the community (referred to henceforth as community-diagnoses). These included OCD, ADHD, anxiety, autism spectrum disorder (ASD), allergies, asthma, tics/Tourette's, schizophrenia/bipolar, depression, concussion, learning difficulties, gastrointestinal problems, headache, trauma, and seizures. 16718 participants had complete demographic and questionnaire information (parent-report: $n=13680$, self-report: $n=3038$ ). 7862 participants (47\% of the total sample) from 3931 families had a family member who also participated in the study; siblings were included in our analyses. Assessments were 30 min and participants were given a small $(<\$ 1$ value) age-appropriate toy. The study was approved by the Hospital for Sick Children's Research Ethics Board. 


\section{Behavioral Measures}

Toronto Obsessive-Compulsive scale (TOCS)

We measured OC and hoarding traits within the last 6 months using the TOCS, a 21-item questionnaire. Each item was scored on a 7-point Likert scale ranging from -3 ('far less often than others of the same age') to +3 ('far more often than others of the same age'). The TOCS has been shown to have high internal consistency (Cronbach's $\alpha=0.94$ ) and to discriminate between an OCD measure (Child Behavior Checklist [CBCL]- Obsessive Compulsive Scale ${ }^{31}$ - Spearman's correlation $=0.5$ ) and an ADHD measure (The Strengths and Weaknesses of ADHD Symptoms and Normal Behavior scale [SWAN] - Spearman's correlation $=0.02$; Park et al., under review). A score of $\geq+2$ on any TOCS item ('more often' or 'far more often' than others of the same age) was used to define a 'symptom' even though these symptoms were based on questionnaires and not clinical interviews.

Two items queried hoarding: 1) excessive acquisition ('Collects useless objects') and 2) difficulty discarding ('Have difficulty throwing things away). Participants were classified as 'hoarding-positive' if they scored $\geq+2$ on both hoarding items and as 'hoarding-negative' if they scored $\leq-2$ on both items. The remaining 19 TOCS items queried non-hoarding OC traits (OC-items). Participants were considered to be 'OC-positive' if they scored $\geq+2$ on at least 3 OC-items (i.e., 3 OC symptoms) - a cut-off supported by previously published ${ }^{32}$ and unpublished (C.A. Mathews and S. Darrow, personal communication) population-based studies. Participants were classified as 'OCnegative' if they scored $\leq-2$ on any OC item. Participants were assigned to one of 4 groups: hoarding- and OC-negative (Control), hoarding-negative and OC-positive (OC-only), hoardingpositive and OC-negative (Hoarding-only) and hoarding- and OC-positive (Hoarding+OC; See Figure 1). We focused our analyses on the extremes of the hoarding and $\mathrm{OC}$ traits to dissociate the two traits as much as possible in order to identify their distinct correlates. To this end, so we excluded participants who did not fall into one of the high/low groups from further analyses. 
CBCL

We used the CBCL anxiety scale (without somatic complaint items) ${ }^{33}$ which consisted of 11 items that each ranged from 0 ('not true') to 2 ('very true or often true'). We calculated the total number of anxiety symptoms (symptom = a score of 2 on an item).

SWAN

We measured ADHD traits using the 18 item SWAN questionnaire. Each item ranged from -3 ('far below compared to people of similar age') to +3 ('far above compared to people of similar age') and these items mirrored the criteria for ADHD in the DSM-IV-TR ${ }^{8}$ with 9 inattentive items and 9 hyperactive/impulsive items. The psychometric properties of the SWAN were described elsewhere ${ }^{30}$. For clarity of interpretation and discussion, SWAN scores were reversed in the analyses such that higher SWAN scores represented higher ADHD traits. We examined the number of inattentive and hyperactive/impulsive ADHD symptoms by counting all items with a score of $\geq+2$ for each dimension separately.

\section{Statistical Analyses}

Statistical analyses were conducted using SAS v9.3. We examined the co-occurrence of hoarding and OC using a chi-squared test. For analyses of gender, age, CBCL anxiety symptoms, community-diagnoses of various psychiatric disorders and ADHD symptoms (inattentive and hyperactive/impulsive separately), we used regression analysis to model outcome measures as a function of hoarding and OC. In the regression framework, a main effect of hoarding without any interaction indicated that Hoarding-only and Hoarding+OC groups differed from the OC-only and Control groups while a main effect of OC meant that the OC-only and Hoarding+OC groups differed from the Hoarding-only and Control groups. An interaction indicated that the difference in the hoarding groups varied as a function of the OC groups or vice versa. 


\section{Insert Figure 1 about here}

We conducted separate mixed model regressions to test if age or sex varied as a function of the hoarding and OC groups while considering respondent as a covariate. Given the results of these analyses, we included age, sex and respondent as covariates in subsequent analyses. All models accounted for within-family correlation using a random effect term.

We examined the frequency of anxiety and ADHD symptoms across hoarding and OC groups using repeated measures logistic regressions for each outcome measure (anxiety, inattentive or hyperactive/impulsive symptoms respectively) with hoarding group, OC group, age, gender, and respondent in the model. When we calculated the mean number of anxiety and ADHD symptoms we first estimated the likelihood of having one symptom for either the CBCL-anxiety scale and each sub-scale of the SWAN. Then we multiplied the estimate by the number of items on the respective scale (anxiety $=11, \mathrm{ADHD}=9$ items on each sub-scale). We used the number of anxiety symptoms as a covariate in the analysis of inattentive symptoms to assess whether anxiety was affecting the relationship between hoarding and inattention ${ }^{34}$. We also used logistic regressions to compare the hoarding and $\mathrm{OC}$ groups on the proportion with a community-diagnoses by comparing participants with each of reported diagnoses against participants without any reported diagnoses $(n=13738)$. We applied Bonferroni correction to $\alpha$ to account for the large number of analyses in the study ( $\alpha$ : $0.05 / 16$ analyses $=0.003$ )

\section{Results}

Hoarding and OC symptoms were common among children from our community sample: 8.9\% (n=1483) were hoarding-positive and 6.1\% (n=1013) was OC-positive. The overlap of hoarding-positive and OC-positive was substantial ( $\mathrm{n}=661 ; 60 \%)$ but not complete, $X^{2}$ 
$(1, n=3930)=936.6, p<0.001$; Table 1$)$. The hoarding-positive group was $10.5 x$ more likely than the hoarding-negative group to be OC-positive (95\%CI: 9.0-12.4). Self-respondents were more likely than parent-respondents to classify themselves as hoarding- and OC-negative (i.e., Control group) and the proportion of Hoarding+OC increased with age in the self-respondent groups (see Supplementary Figure 1).

Insert Table 1 about here

Supplementary Table 1 summarizes the regression analyses. There was a main effect of hoarding $\left(\mathrm{F}_{(1,3922)}=24.0, p<0.001 ; \mathrm{OR}=1.5[95 \% \mathrm{CI}=1.29-1.79]\right)$, but not of OC on gender: Hoardingonly and Hoarding+OC groups were more likely than OC-only and Control groups to be female. There was a main effect of OC on age $\left(\mathrm{F}_{(1,3922)}=15.1, p<0.001, \beta=0.36[\mathrm{SE} \pm 0.09]\right)$ : OC-only and Hoarding+OC groups were older than the Hoarding-only and Control groups. There was a significant interaction between hoarding and respondent $\left(\mathrm{F}_{(1,3915)}=22.37, p<0.001\right)$. When parents responded, the hoarding-positive groups were 0.4 years younger than the hoarding-negative groups $(p<0.001 ; \mathrm{SE} \pm 0.09)$ whereas when participants responded, the hoarding-positive groups were 0.5 years older than the hoarding-negative groups ( $p=0.004 ; \mathrm{SE} \pm 0.19)$. Only the relationship for parent-respondents survived Bonferroni correction.

As shown in Table 1, the hoarding-positive groups (Hoarding-only and Hoarding+OC) had a greater reported prevalence of an OCD community-diagnosis than hoarding-negative groups (OConly and Control; main effect of hoarding: $\left.\mathrm{OCD}: F_{(1,3379)}=12.67, p=0.001, \mathrm{OR}=4.6[95 \% \mathrm{CI}=1.3-16.7]\right)$. The OC-positive groups (Hoarding+OC and OC-only) also had a greater reported prevalence of an OCD community-diagnosis than the OC-negative groups (Hoarding-only and Control; main effect of OC: $\left.F_{(1,3379)}=10.76, p=0.001, \mathrm{OR}=14.7[95 \% \mathrm{CI}=4.0-52.6]\right)$. There was no significant interaction for OCD community-diagnosis but there was for anxiety symptoms $\left(F_{(1,3881)}=11.1, p<0.001\right)$. The 
Hoarding+OC group had significantly more reported symptoms than any other group $\left(p^{\prime} \mathrm{s}<0.001\right.$, OR's: $2.0-17.2$ ). The OC-only group had more reported anxiety symptoms than the Hoarding-only group $(p<0.001 ;$ OR[95\%CI=2.7[2.2-3.3]).

As shown in Table 2, the four groups differed on the estimated frequency of communitydiagnoses. The hoarding-positive groups (Hoarding+OC and Hoarding-only) were more likely than the hoarding-negative groups (OC-only and Control) to have a community-diagnosis of ASD, anxiety, ADHD, tics/Tourette's, or any diagnosis (main effect of hoarding: $p$ 's all <0.01). The effect for tics/Tourette's was no longer significant after applying the Bonferroni correction. OC-positive groups (Hoarding+OC and OC-only) also were more likely than the OC-negative groups (Hoardingonly and Control) to have a community-diagnosis of ASD, anxiety, ADHD, depression, tics/Tourette's, or any diagnosis (main effect of OC: $p$ 's all <0.01). The relationship for depression was no longer significant after Bonferroni correction. There was no significant interaction between hoarding and OC groups for any disorder. However there was a clear trend for the Hoarding+OC group to have the highest prevalence of many of the disorders, specifically ADHD and any diagnosis. ADHD is the only disorder where the prevalence was greater in the Hoarding-only group than the OC-only group. There was no effect of hoarding or OC for allergies, asthma, concussions or seizures. We could not run models for schizophrenia/bipolar, learning difficulties, headaches, trauma and gastrointestinal problems because of the low prevalence of each disorder $(\leq 0.004 \%)$.

Insert Table 2 about here

As show in Figure 2, hoarding-positive groups (Hoarding+OC and Hoarding-only) had more reported inattentive and hyperactive/impulsive symptoms than hoarding-negative groups (OC-only and Control; main effect of hoarding for both traits: $p<0.001)$. Similarly, OC-positive groups (Hoarding+OC and OC-only) had more reported inattentive and hyperactive/impulsive symptoms 
than OC-negative groups (Hoarding-only and Control; main effect for OC for both traits: $p \leq 0.01$ ) although the relationship between OC and inattention did not survive Bonferroni correction. More inattentive, but not hyperactive/impulsive, symptoms were reported in the Hoarding-only compared to the OC-only groups ( $p=0.003, \mathrm{OR}[95 \% \mathrm{CL}]=1.52[1.15-2.02])$. When number of anxiety symptoms were added to the model, the main effect of hoarding on number of inattentive symptoms was still significant (main effect of hoarding: $F_{(1,3392)}=14.98, p<0.001$; main effect of anxiety: $F_{(1,3392)}=67.24, p<0.001$; data not shown) and the increased number of inattentive symptoms in the Hoarding-only than the OC-only group remained significant $(p<0.001$; OR[95\%CL] $=1.86[1.40-2.48])$.

Insert Figure 2 about here

\section{Discussion}

This study is the first to examine the correlates of high hoarding with and without high OC symptoms in children and adolescents in the community. We demonstrated that hoarding existed in the absence of OC symptoms in $40 \%$ of youth. Approximately $10 \%$ of our participants were classified as hoarding-positive (both hoarding symptoms; a score $\geq+2$ on both hoarding items) and over $40 \%$ of these participants were classified as OC-negative (no OC symptoms; scores $\leq-2$ on all OC-items). These results suggest that 1) hoarding should not only be studied in the context of OCD and 2) hoarding in children may be underdiagnosed. Participants with hoarding, but not OC, symptoms with concomitant impairment might have been missed by DSM-IV in which hoarding was a subtype of $\mathrm{OCD}^{8}$. In the entire sample, $0.8 \%(\mathrm{n}=140)$ had a community-diagnosis of OCD, which is in the range reported by previous population-based studies that used diagnostic interviews 32,35 . The majority of the participants in the four groups with a community-diagnosis of 
OCD were in the OC-only and Hoarding+OC groups but reported OCD was almost completely absent in the Control and Hoarding-only groups. Whether the lack of a community-diagnosis of OCD in the Hoarding-only group was because they were not assessed, or did not show impairment or an OCD diagnoses was just not reported by parents or participants is unclear. Regardless of the reason, our findings imply that youth with hoarding symptoms, but not OC symptoms, are unlikely to get a diagnosis of OCD in the community.

Hoarding and OC symptoms did co-occur. Many hoarding-positive participants were OCpositive (60\%; See Figure1). The combination of high hoarding and OC symptoms resulted in the greatest number of anxiety symptoms and the greatest prevalence of several community psychiatric or medical disorders. For example, the Hoarding+OC group was $7 \mathrm{x}$ more likely to have ADHD (15\% vs. $3 \%$ ) and 5.5x was more likely to have any diagnosis (31\% vs. $8 \%$ ) than the Control group. The high rates of various disorders, particularly ADHD and any diagnosis, in the Hoarding+OC group compared to all other groups are clinically significant even though the interaction between hoarding and OC was not statistically significant. Similarly, clinical studies show that pediatric patients with OCD and hoarding have worse outcomes such as the most severe, or the largest total number of obsessions and compulsions, or the earliest age of OCD diagnosis $12,14,36$. These findings are not surprising given the association between comorbidity and severity ${ }^{17}$ and, with our data, suggest that hoarding may be a poor prognostic factor in the presence of OCD or OC symptoms as shown in previous studies ${ }^{37-39}$.

Hoarding and OC groups differed in terms of their demographic correlates. The proportion of females was similar in OC-positive and -negative groups; however, females were more likely than males to hoard. More hoarding in female than male participants was also reported in a community-based study of adolescents ${ }^{4}$ and clinical studies of youth with ADHD or OCD 12,14,19,36. OCpositive groups were more likely than OC-negative groups to be older while the effect of hoarding on age depended upon respondent-type. Hoarding-positive groups (Hoarding+OC and Hoarding- 
only) were more likely to be younger in the parent-respondent group but only by a few months. This finding suggests we were not just capturing developmentally appropriate hoarding typically seen in younger children ${ }^{40}$ in our hoarding-positive groups. In two previous clinic studies, no age differences were observed between groups with and without hoarding symptoms ${ }^{12,14}$ while age was not examined in any community pediatric samples.

Anxiety and ADHD distinguished the Hoarding-only and OC-only groups. Anxiety symptoms were more common in the OC-only compared to the Hoarding-only groups and a similar trend was observed for the community-diagnosis of anxiety. ADHD was the only community-diagnosis more prevalent in the Hoarding-only than the OC-only group. This difference was likely driven by the inattentive, not hyperactive/impulsive symptoms. Several studies $13,19,23,36,41$, but not all4,12,42, support a relationship between hoarding and ADHD. Similar to our findings, inattention was linked to hoarding in multiple studies in adults $10,20,23,43$. It was difficult to determine if hoarding and ADHD existed in the absence of OCD in previous studies that used clinical samples of patients with OCD. Our findings demonstrate that hoarding was independently associated with ADHD and specifically inattentive symptoms. The explanation for the link between inattention and hoarding is unclear. One possibility is that inattention that presents with hoarding symptoms may just be anxiety because anxiety can present in a similar fashion to inattention ${ }^{34}$ and anxiety is associated with hoarding symptoms ${ }^{10}$. In our study, the relationship between inattention and hoarding was not the result of anxiety symptoms which suggests that inattention in hoarding may not be an epiphenomenon of anxiety. One implication of the relationship between hoarding and inattention is that these traits may share cognitive 22,28 and therefore biological underpinnings.

Aside from ADHD and anxiety, hoarding and OC shared many clinical correlates. Hoardingpositive and OC-positive groups were associated with elevated rates of many of the queried psychiatric and medical community-diagnoses. Approximately $20 \%$ of the hoarding-positive groups 
(Hoarding+OC and Hoarding-only) had at least one community-diagnosis, which may indicate that hoarding in children and adolescents increases the risk for psychiatric or other illnesses. In contrast, previous studies of clinical and community-based samples report a general lack of psychiatric conditions in children and adolescents presenting with hoarding symptoms ${ }^{4,12,14,19}$. One possibility for the incongruent findings is that in clinical samples the overall rate of comorbid disorders is already higher than the population prevalence ${ }^{15,44}$ and a ceiling effect may prevent additional hoarding symptoms from increasing the risk for comorbid disorders. A previous community-based study 4 found no increased risk of psychiatric disorders associated with hoarding, however the sample only included 15 year old twins which may not broadly represent children and adolescents.

Some limitations of our study should be considered. Our measure of hoarding was relatively simple compared to the currently-available instruments (e.g., the Children's Saving Inventory CSI 45 that measure multiple dimensions of hoarding). We only used 'difficulty discarding' and 'excessive acquisition' as criteria for hoarding. "Clutter" is difficult to assess in children because parents can often control the degree of clutter ${ }^{16}$ and impairment can be difficult to assess in nonclinical assessments. Our measure was based on self- or parent-report instead of clinical assessment and did not assess impairment which would have provided important information about the impact of hoarding symptoms. Our analyses also only considered the high and low scorers on hoarding and OC symptoms rather than the full distributions of these traits. Whether hoarding and $\mathrm{OC}$ symptoms are in fact continuous traits in the general population is an important question but was not the focus of this study. Our sample was cross-sectional (6 month window) not longitudinal which may have been a limiting factor because OC symptoms can wax and wane ${ }^{46}$. Despite the limitations, our study was the first to examine the overlap of hoarding and OC symptoms in a pediatric community-sample and we were able to make important predictions about 
clinical correlates and our findings align with several previous studies in the field as discussed above.

In summary, hoarding symptoms existed in the absence of OC symptoms in a large proportion of youth from the community although hoarding was observed in presence of OC symptoms. Participants with combined hoarding and OC symptoms showed the highest prevalence of many comorbid disorders (e.g., ADHD, ASD, and anxiety). Hoarding alone had unique clinical correlates, particularly more inattentive ADHD symptoms and fewer anxiety symptoms. The relationship between hoarding and ADHD suggests possible shared cognitive mechanisms and neurobiological etiologies or the relationship could be an epiphenomenon. Understanding the mechanisms underlying hoarding could improve our ability to detect and treat hoarding across the lifespan. Importantly, hoarding existed in the absence of both OC and ADHD symptoms. The majority of hoarding participants did not have a reported diagnosis of OCD or ADHD and thus measures for these disorders would not account for all individuals that hoard. The use of specialized measures for both adults and children, such as the Savings Inventory Revised (SIR $\left.{ }^{47}\right)$ and the CSI ${ }^{45}$, should be used when investigating hoarding instead of the traditional OCD measures. Using tools designed for hoarding will hopefully permit more accurate identification of these behaviors both in adults and children. Hoarding in adulthood is associated with many negative outcomes (strained family relationships, health risks, loss of home and/or life ${ }^{48-50}$ ) and thus identifying and addressing hoarding symptoms early could help change trajectories to circumvent impairment later in life.

\section{Clinical Guidance}

- Hoarding symptoms are relatively common in children and adolescents

- Hoarding symptoms can present independently of OCD in youth

- Hoarding may be specifically related to inattentive ADHD symptoms

- Presence of hoarding symptoms may be a poor prognostic factors in your pediatric patients 


\begin{tabular}{|c|c|c|c|c|c|}
\hline & Control & OC-only & Hoarding-only & Hoarding+OC & Significant Effects \\
\hline $\mathrm{n}$ & 2476 & 352 & 441 & 661 & \\
\hline Female $(\%, 95 \% \mathrm{CI})$ & $48.8(46.0-51.4)$ & $46.3(41.0-51.6)$ & $58.9(54.0-63.8)$ & $56.8(52.8-60.7)$ & $\mathrm{H}^{* *}$ \\
\hline \multicolumn{6}{|l|}{ Age (mean,95\%CI) } \\
\hline Self-Respondent & $14.6(14.4-14.8)$ & $15.0(14.8-15.2)$ & $15.2(14.8-15.5)$ & $15.5(15.2-15.8)$ & $\mathrm{H} \times \operatorname{Resp}^{* *} ; \mathrm{OC}^{* *}$ \\
\hline Parent-Respondent & $10.2(10.1-10.3)$ & $10.6(10.4-10.8)$ & $9.8(9.6-10.0)$ & $10.2(10.0-10.3)$ & \\
\hline $\begin{array}{l}\text { Anxiety symptoms (mean, } \\
95 \% \mathrm{CI} \text { ) }\end{array}$ & $0.2(0.2-0.3)$ & $1.7(1.5-1.9)$ & $0.7(0.6-0.8)$ & $2.8(2.7-3.0)$ & $\mathrm{H} x \mathrm{OC}^{* *}$ \\
\hline $\begin{array}{l}\text { Community OCD diagnosis } \\
(\%, 95 \% \mathrm{CI}) \\
\mathrm{N}=140(0.8 \%) \#\end{array}$ & $0.2(0.1-0.3)$ & $1.1(0.8-1.5)$ & $0.2(0.09-1.3)$ & $4.7(2.7$ & $\mathrm{H}^{*} ; \mathrm{OC}^{* *}$ \\
\hline
\end{tabular}

Table 1: Hoarding and Obsessive-Compulsive (OC) Groups: Demographics and OCD-related Outcomes

Results of regressions that examined the main effects of hoarding, $\mathrm{OC}$ and hoarding $\mathrm{x}$ OC interactions. $\mathrm{H}=$ main effect of hoarding; $\mathrm{OC}$ = main effect of $\mathrm{OC} ; \mathrm{H} \times \mathrm{Resp}=$ interaction of hoarding and respondent, $\mathrm{H}$ x OC = hoarding x OC interaction. Age, sex, respondent were covariates in the analysis of anxiety symptoms and OCD diagnosis. ${ }^{*} p<0.05,{ }^{* *} p<0.01$. \# = prevalence in total sample $(\mathrm{n}=16718) . \mathrm{CI}=$ confidence interval, $\mathrm{TOCS}=$ Toronto Obsessive-Compulsive Scale; $\mathrm{OCD}=$ obsessive-compulsive disorder. 


\begin{tabular}{|c|c|c|c|c|c|}
\hline $\begin{array}{l}\text { Disorder } \\
\text { \%(freq. in whole } \\
\text { sample) }\end{array}$ & $\begin{array}{l}\text { Control } \\
(\% ; 95 \% \mathrm{CI})\end{array}$ & $\begin{array}{l}\text { OC-Only } \\
(\% ; 95 \% \mathrm{CI})\end{array}$ & $\begin{array}{l}\text { Hoarding-Only } \\
(\% ; 95 \% \mathrm{CI})\end{array}$ & $\begin{array}{l}\text { Hoarding+OC } \\
(\% ; 95 \% \mathrm{CI})\end{array}$ & $\begin{array}{r}\text { Significant } \\
\text { Main Effects }\end{array}$ \\
\hline $\bar{n}$ & 2476 & 352 & 441 & 661 & \\
\hline $\begin{array}{l}\text { Allergies } \\
0.3 \%(n=48)\end{array}$ & $0.3(0.1-0.9)$ & $0.3(0.1-2.5)$ & $0.3(0.1-2.5)$ & $0.5(0.1-2.2)$ & \\
\hline $\begin{array}{l}\text { ASD } \\
1.3 \%(n=222)\end{array}$ & $0.03(0.02-0.2)$ & $1.0(0.4-2.4)$ & $0.4(0.1-1.3)$ & $4.3(2.5-7.3)$ & $\mathrm{H}^{* *}, \mathrm{OC}^{* *}$ \\
\hline $\begin{array}{l}\text { Asthma } \\
0.7 \%(n=118)\end{array}$ & $0.6(0.3-1.2)$ & $1.5(0.6-3.9)$ & $1.6(0.5-4.4)$ & $0.6(0.6-3.4)$ & \\
\hline $\begin{array}{l}\text { Anxiety } \\
3.5 \%(\mathrm{n}=578)\end{array}$ & $0.9(0.5-1.4)$ & $4.4(2.7-7.1)$ & $2.7(1.6-4.8)$ & $13.0(9.9-16.9)$ & $\mathbf{H}^{* *}, \mathbf{O C}^{* *}$ \\
\hline $\begin{array}{l}\text { ADHD } \\
6.1 \%(\mathrm{n}=1026)\end{array}$ & $2.5(1.9-3.4)$ & $3.2(1.9-5.5)$ & $7.3(5.1-10.4)$ & $15.6(12.2-19.6)$ & $\mathbf{H}^{* *}, \mathbf{O C}^{* *}$ \\
\hline $\begin{array}{l}\text { Tics/Tourette's } \\
1.1 \%(\mathrm{n}=192)\end{array}$ & $0.3(0.2-0.7)$ & $0.7(0.2-2.2)$ & $0.6(0.2-1.9)$ & $3.0(1.6-5.5)$ & $\mathbf{H}^{*}, \mathbf{O C} * *$ \\
\hline $\begin{array}{l}\text { Depression } \\
1.2 \%(\mathrm{n}=196)\end{array}$ & $0.4(0.2-0.8)$ & $1.9(0.9-3.9)$ & $0.5(0.1-2.2)$ & $3.4(1.9-6.0)$ & $\mathrm{OC}^{*}$ \\
\hline $\begin{array}{l}\text { Concussion } \\
2.8 \%(n=474)\end{array}$ & $2.4(1.7-3.5)$ & $4.1(2.4-6.9)$ & $3.3(1.7-6.2)$ & $5.2(3.4-7.9)$ & \\
\hline $\begin{array}{l}\text { Seizures } \\
1.3 \%(\mathrm{n}=218)\end{array}$ & $0.7(0.4-1.4)$ & $1.1(0.3-3.1)$ & $0.7(0.2-2.4)$ & $2.3(1.2-4.4)$ & \\
\hline $\begin{array}{l}\text { Any diagnosis } \\
17.8 \%(\mathrm{n}=2980)\end{array}$ & $7.5(6.3-8.9)$ & $13.2(10.7-17.1)$ & $13.9(10.7-17.8)$ & $30.9(26.9-35.2)$ & $\mathrm{H}^{* *}, \mathrm{OC}^{* *}$ \\
\hline
\end{tabular}

Table 2. Proportion of Community Psychiatric and Medical Diagnoses as a Function of Hoarding and Obsessive-Compulsive (OC) Groups

Age, sex, respondent were covariates in each analysis. Any diagnosis = any community diagnosis. Control = Hoarding- and OC-negative; OC-only = hoarding-negative and OC-positive; H-only: hoarding-positive and OC-negative; $\mathrm{H}+\mathrm{OC}$ : hoarding- and OC-positive. $\mathrm{H}=$ main effect of hoarding, $\mathrm{OC}=$ main effect of OC. There were no significant interactions. ${ }^{*} p<0.05,{ }^{* *} p<0.001$. ASD $=$ autism spectrum disorder, OCD = obsessive-compulsive disorder, ADHD = attention-deficit/hyperactivity disorder, $\mathrm{CI}=$ confidence interval. Frequencies from the whole sample $(\mathrm{n}=16718)$ are shown as a reference and were not included in any statistical analysis 
Figure 1: Hoarding and Obsessive-Compulsive (OC) Symptoms. The proportion of participants with and without hoarding symptoms (hoarding-positive and hoarding-negative respectively) and with and without at least OC symptoms (OC-positive and OC-negative respectively) which results in four groups: Hoarding- and OC-negative (Control), hoarding-negative and OC-positive (OC-only), hoarding-positive and OC-negative (Hoarding-only) and hoarding- and OC-positive (Hoarding+OC).

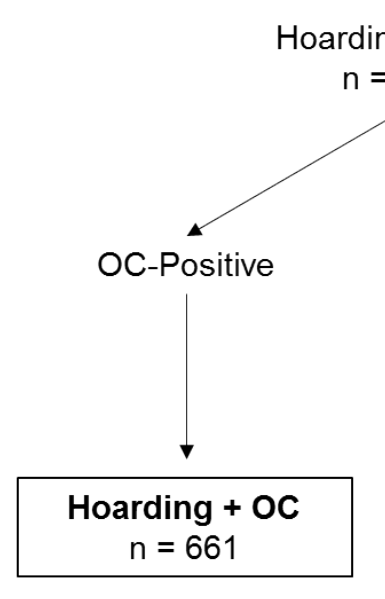

$n=1483$

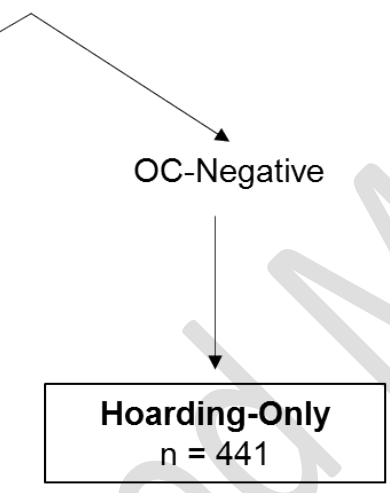

Hoarding-Negative

$\mathrm{n}=3313$

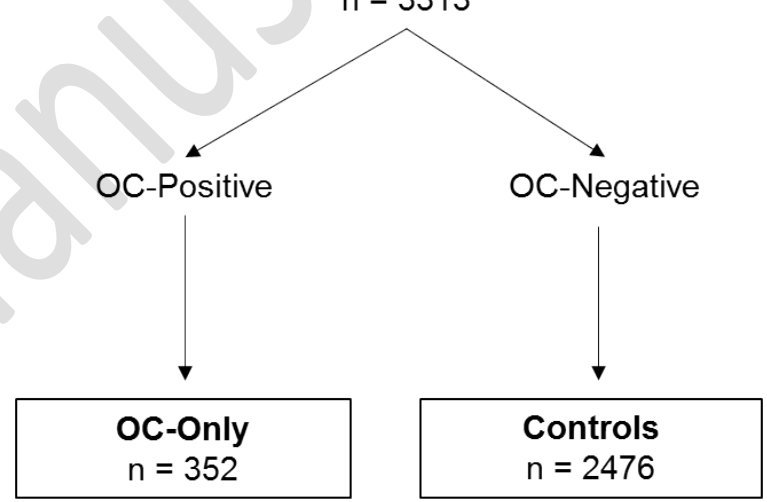


Figure 2: Attention-Deficit/Hyperactivity Disorder (ADHD) Symptoms. Hoarding-positive and OC-positive groups were associated with a greater estimated mean number of inattentive (Panel A) and hyperactive/impulsive symptoms (Panel B) (main effect of hoarding and OC $p$ 's $<0.001$ ) although the relationship between OC and inattentive symptoms did not survive Bonferroni correction. More inattentive, but not hyperactive/impulsive, symptoms were observed in the Hoarding-only compared to the OC-only group $\left({ }^{*} \mathrm{p}<0.05\right)$. The estimated mean number of symptoms was calculated by multiplying the proportion of symptoms predicted from the model by the total number of symptoms for each scale (9). Control = Hoarding- and OC-negative $(n=2476)$; OC-only = hoarding-negative and OC-positive ( $\mathrm{n}=352)$; H-only: hoarding-positive and OC-negative $(n=441) ; H+O C$ : hoarding- and OC-positive $(n=661)$. Age, sex, respondent were covariates in each analysis. $\mathrm{CI}=$ confidence intervals.

Inattentive

Symptoms
Hyperactive/lmpulsive

Symptoms

B

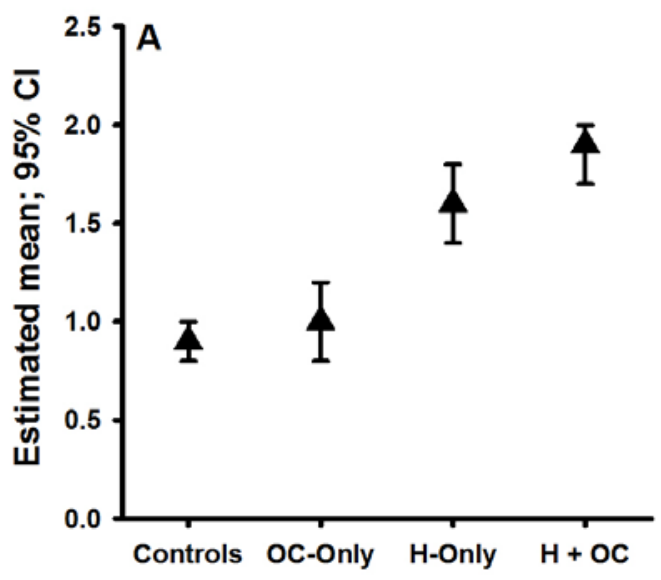





\section{SUPPLEMENTAL MATERIAL}

Supplementary Table 1) Regression tables for Analyses. Age, gender and respondent were included in models for all questionnaires, psychiatric/medical outcomes (data not shown). Hoarding = main effect of hoarding, $\mathrm{OC}=$ main effect of obsessive-compulsive features, $\mathrm{H} \mathrm{X} \mathrm{OC=}$ hoarding $\mathrm{x}$ OC interaction, Hoarding $\mathrm{x}$ Parent-respondent = hoarding $\mathrm{x}$ respondent interaction. Control = Hoarding- and OC-negative; OC-only = hoarding-negative and OC-positive; H-only: hoarding-positive and OC-negative; $\mathrm{H}+\mathrm{OC}$ : hoarding- and OC-positive. $\mathrm{dx}=$ diagnosis, $\mathrm{OR}=\mathrm{odds}$ ratio, $\mathrm{CI}=$ confidence interval, $\mathrm{df}=$ degrees of freedom. ${ }^{* *}=p<0.003$ (significant after Bonferroni correction), ${ }^{*}=p<0.05$ (not significant after Bonferroni correction). For age we report $\beta$ for the main effects and the sub-groups to explain the significant interaction between hoarding and respondent. Parent: hoard vs. non-hoard compared the hoarding and non-hoarding groups within parent respondent only and the same for self-respondent. 


\begin{tabular}{|c|c|c|c|c|c|}
\hline & Predictors & OR (95\%CI) & $\mathbf{T}$ & df & p-value \\
\hline Female & Hoarding & $1.5(1.3-1.8)$ & 3.1 & 3925 & $0.001^{* *}$ \\
\hline \multirow[t]{3}{*}{ Mixed-model Logistic Regression } & $\mathrm{OC}$ & $0.9(0.8-1.1)$ & -0.7 & 3925 & 0.47 \\
\hline & Hoarding $\mathrm{x} \mathrm{OC}$ & $\mathrm{n} / \mathrm{a}$ & -0.04 & 3925 & 0.96 \\
\hline & Parent-respondent & $1.9(1.5-2.2)$ & -6.5 & 3925 & $<0.001^{* *}$ \\
\hline Age & OC & $\beta=0.4 ; \mathrm{SE} \pm 0.09$ & -3.9 & 3922 & $<0.001^{* *}$ \\
\hline \multirow[t]{3}{*}{ Linear Mixed-model Regression } & Hoarding $\mathrm{x}$ Parent-Respondent & $\mathrm{n} / \mathrm{a}$ & -4.7 & 3915 & $<0.001^{* *}$ \\
\hline & Parent: Hoard(+) vs. Hoard(-) & $\beta=-0.4 ; \mathrm{SE} \pm 0.1$ & -4.3 & 3909 & $<0.001^{* *}$ \\
\hline & Self: Hoard(+) vs. Hoard(-) & $\beta=0.5 ; \mathrm{SE} \pm 0.2$ & 2.9 & 3918 & $0.004^{*}$ \\
\hline CBCL-Anxiety & Hoarding X OC & $\mathrm{n} / \mathrm{a}$ & -3.3 & 3882 & $<0.001^{* *}$ \\
\hline \multirow{3}{*}{ Repeated Logistic Regression } & Hoard+OC vs. Hoard-only & $5.4(4.5-6.6)$ & 17.3 & 3923 & $<0.001^{* *}$ \\
\hline & Hoard+OC vs. OC-only & $2.0(1.7-2.4)$ & 9.2 & 3920 & $<0.001^{* *}$ \\
\hline & Hoard+OC vs. Control & $17.2(14.7-20.0)$ & 37.7 & 3670 & $<0.001^{* *}$ \\
\hline OCD community-dx & Hoarding & $4.6(1.3-16.7)$ & 3.6 & 3379 & $<0.001^{* *}$ \\
\hline \multirow[t]{2}{*}{ Repeated Logistic Regression } & OC & $14.7(4.0-52.6)$ & 3.3 & 3379 & $<0.001^{* *}$ \\
\hline & Hoarding X OC & $\mathrm{n} / \mathrm{a}$ & 1.0 & 3379 & 0.31 \\
\hline Allergies community- $\mathrm{dx}$ & Hoarding & $1.30(0.26-6.58)$ & 0.3 & 3347 & 0.73 \\
\hline \multirow{2}{*}{ Repeated Logistic Regression } & OC & $1.41(0.27-7.46)$ & 0.5 & 3347 & 0.69 \\
\hline & Hoarding X OC & $\mathrm{n} / \mathrm{a}$ & 0.2 & 3347 & 0.85 \\
\hline ASD community-dx & Hoarding & $5.92(2.63-13.16)$ & 3.7 & 1273 & $<0.001^{* *}$ \\
\hline \multirow[t]{2}{*}{ Repeated Logistic Regression } & OC & $13.51(5.99-30.30)$ & 4.3 & 3396 & $<0.001^{* *}$ \\
\hline & Hoarding X OC & $\mathrm{n} / \mathrm{a}$ & -0.7 & 3396 & 0.50 \\
\hline Asthma community-dx & Hoarding & $1.65(0.71-3.85)$ & 0.1 & 953 & 0.94 \\
\hline \multirow[t]{2}{*}{ Repeated Logistic Regression } & $\mathrm{OC}$ & $1.55(0.63-3.82)$ & 0.2 & 1845 & 0.87 \\
\hline & Hoarding X OC & $\mathrm{n} / \mathrm{a}$ & -1.3 & 1540 & 0.20 \\
\hline Anxiety community-dx & Hoarding & $3.13(2.08-4.72)$ & 4.5 & 2284 & $<0.001^{* *}$ \\
\hline \multirow[t]{2}{*}{ Repeated Logistic Regression } & $\mathrm{OC}$ & $5.13(3.78-7.75)$ & 5.6 & 3500 & $<0.001^{* *}$ \\
\hline & Hoarding X OC & $\mathrm{n} / \mathrm{a}$ & 0.2 & 3500 & 0.86 \\
\hline ADHD community- $d x$ & Hoarding & $4.07(2.88-5.75)$ & 6.0 & 3605 & $<0.001^{* *}$ \\
\hline \multirow[t]{2}{*}{ Repeated Logistic Regression } & OC & $1.73(1.2-2.46)$ & 4.1 & 2212 & $<0.001^{* *}$ \\
\hline & Hoarding X OC & $\mathrm{n} / \mathrm{a}$ & 1.8 & 3605 & 0.08 \\
\hline Tics/Tourette's community-dx & Hoarding & $2.82(1.29-6.17)$ & 2.5 & 2140 & $<0.01$ \\
\hline \multirow[t]{2}{*}{ Repeated Logistic Regression } & OC & $3.43(1.55-7.52)$ & 2.9 & 2939 & $<0.001^{* *}$ \\
\hline & Hoarding X OC & $\mathrm{n} / \mathrm{a}$ & 0.9 & 3381 & 0.35 \\
\hline Depression community-dx & Hoarding & $1.57(1.02-2.75)$ & 1.7 & 747 & 0.10 \\
\hline \multirow[t]{2}{*}{ Repeated Logistic Regression } & $\mathrm{OC}$ & $5.68(2.38-13.51)$ & 2.5 & 3391 & $0.01^{*}$ \\
\hline & Hoarding X OC & $\mathrm{n} / \mathrm{a}$ & 0.4 & 3391 & 0.71 \\
\hline Concussion community-dx & Hoarding & $1.32(0.82-5.05)$ & 0.8 & 1488 & 0.44 \\
\hline \multirow[t]{2}{*}{ Repeated Logistic Regression } & $\mathrm{OC}$ & $1.67(1.02-2.75)$ & 1.2 & 3446 & 0.21 \\
\hline & Hoarding X OC & $\mathrm{n} / \mathrm{a}$ & -0.1 & 3011 & 0.89 \\
\hline \multirow{3}{*}{$\begin{array}{l}\text { Seizures community-dx } \\
\text { Repeated Logistic Regression }\end{array}$} & Hoarding & $1.4(0.61-3.27)$ & 1.3 & 2279 & 0.19 \\
\hline & OC & $2.1(0.90-5.05)$ & 1.8 & 3377 & $0.07^{*}$ \\
\hline & Hoarding X OC & $\mathrm{n} / \mathrm{a}$ & 1.0 & 3377 & 0.32 \\
\hline Any community-dx & Hoarding & $2.42(1.92-3.05)$ & 6.2 & 3339 & $<0.001^{* *}$ \\
\hline \multirow[t]{2}{*}{ Repeated Logistic Regression } & $\mathrm{OC}$ & $2.29(1.81-2.89)$ & 6.2 & 3697 & $<0.001^{* *}$ \\
\hline & Hoarding X OC & $\mathrm{n} / \mathrm{a}$ & 1.7 & 3923 & 0.09 \\
\hline ADHD - inattention & Hoarding & $1.95(1.66-2.30)$ & 5.5 & 3923 & $<0.001^{* *}$ \\
\hline \multirow{2}{*}{ Repeated Logistic Regression } & OC & $1.28(1.09-1.51)$ & 2.5 & 3923 & $0.01^{*}$ \\
\hline & Hoarding X OC & $\mathrm{n} / \mathrm{a}$ & 0.6 & 3923 & 0.58 \\
\hline ADHD - hyperactivity/impulsivity & Hoarding & $2.47(2.06-2.95)$ & 6.7 & 3923 & $<0.001^{* *}$ \\
\hline \multirow[t]{2}{*}{ Repeated Logistic Regression } & OC & $2.26(1.89-2.7)$ & 6.4 & 3923 & $<0.001^{* *}$ \\
\hline & Hoarding X OC & $\mathrm{n} / \mathrm{a}$ & 0.1 & 3923 & 0.91 \\
\hline
\end{tabular}




\section{Suplementary Figure S1. Proportion of participants in hoarding and obsessive-compulsive (OC) groups by age and respondent.}

Note: If parents rather than youth themselves filled out the TOCS, the participants were more likely to be classified as hoarding-negative and OC-negative. Within parent respondent and selfrespondent groups, the proportion of participants was quite similar, except that the proportion of hoarding+OC increased with age in the self-respondent groups. The numbers in the $\mathrm{x}$-axis label refer to age in years. Control = hoarding-negative and OC-negative; H-only = hoarding-positive and OC-negative; $\mathrm{H}+\mathrm{OC}$ = hoarding positive and OC-positive; OC-only = hoarding-negative and OCpositive; Parent = parent-respondent; Self = self-respondent.

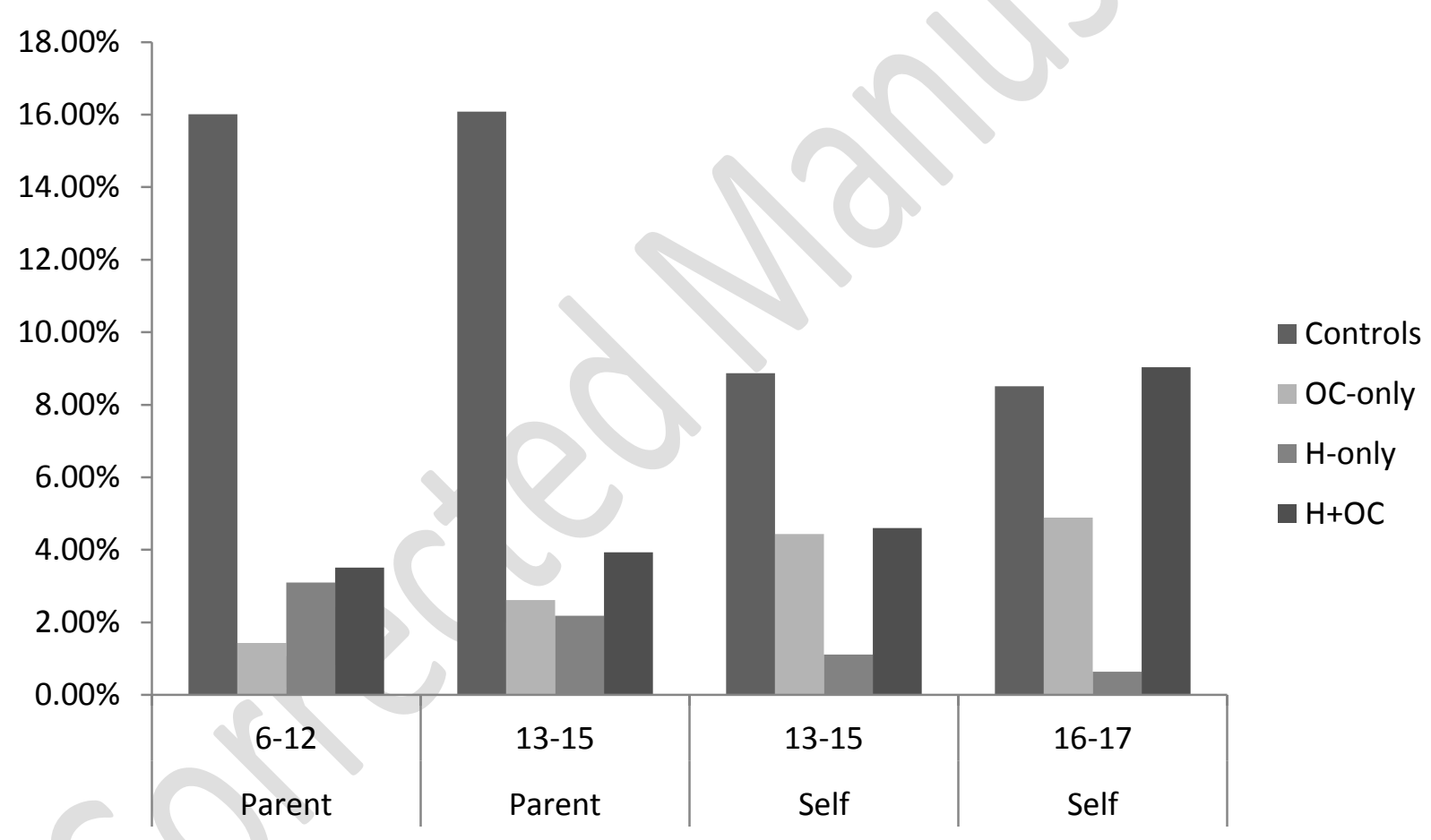




\section{References}

1. Frost RO, Gross RC. The hoarding of possessions. Behav Res Ther. May 1993;31(4):367-381.

2. Frost RO, Kim HJ, Morris C, Bloss C, Murray-Close M, Steketee G. Hoarding, compulsive buying and reasons for saving. Behav Res Ther. Jul-Aug 1998;36(7-8):657-664.

3. Samuels JF, Bienvenu OJ, Grados MA, et al. Prevalence and correlates of hoarding behavior in a community-based sample. Behaviour research and therapy. Jul 2008;46(7):836-844.

4. Ivanov VZ, Mataix-Cols D, Serlachius E, et al. Prevalence, comorbidity and heritability of hoarding symptoms in adolescence: a population based twin study in 15-year olds. PLoS ONE. 2013;8(7):e69140.

5. Tolin DF, Meunier SA, Frost RO, Steketee G. Course of compulsive hoarding and its relationship to life events. Depression and anxiety. Sep 2010;27(9):829-838.

6. Samuels JF, Bienvenu OJ, Pinto A, et al. Hoarding in obsessive-compulsive disorder: Results from the OCD Collaborative Genetics Study. Behaviour Research and Therapy. 2007;45(4):673-686.

7. Samuels J, Bienvenu OJ, 3rd, Riddle MA, et al. Hoarding in obsessive compulsive disorder: results from a case-control study. Behav Res Ther. May 2002;40(5):517-528.

8. American Psychiatric Association, ed Diagnostic and statistical manual of mental disorders. 4th ed., text rev. ed. Washington, DC: American Psychiatric Publishing; 2000.

9. American Psychiatric Association. Diagnositic and statistical manual of mental disorders. 5th ed. Arlington, VA: American Psychiatric Publishing; 2013.

10. Frost RO, Steketee G, Tolin DF. Comorbidity in hoarding disorder. Depression and Anxiety. 2011;28(10):876-884.

11. Pertusa A, Frost RO, Fullana MA, et al. Refining the diagnostic boundaries of compulsive hoarding: A critical review. Clinical Psychology Review. 2010;30(4):371-386.

12. Storch EA, Lack CW, Merlo LJ, et al. Clinical features of children and adolescents with obsessive-compulsive disorder and hoarding symptoms. Comprehensive Psychiatry. 2007;48(4):313-318.

13. Sheppard B, Chavira D, Azzam A, et al. ADHD prevalence and association with hoarding behaviors in childhood-onset OCD. Depression and Anxiety. 2010;27(7):667-674.

14. Samuels J, Grados MA, Riddle MA, et al. Hoarding in Children and Adolescents with Obsessive-Compulsive Disorder. J Obsessive Compuls Relat Disord. Oct 1 2014;3(4):325-331.

15. Berkson J. Limitations of the application of fourfold table analysis to hospital data. Biometrics. Jun 1946;2(3):47-53.

16. Storch EA, Rahman O, Park JM, Reid J, Murphy TK, Lewin AB. Compulsive hoarding in children. Journal of Clinical Psychology. 2011;67(5):507-516.

17. Caron C, Rutter M. Comorbidity in child psychopathology: concepts, issues and research strategies. Journal of child psychology and psychiatry, and allied disciplines. Nov 1991;32(7):1063-1080.

18. Abramovitch A, Dar R, Mittelman A, Wilhelm S. Comorbidity Between Attention Deficit/Hyperactivity Disorder and Obsessive-Compulsive Disorder Across the Lifespan: A Systematic and Critical Review. Harvard review of psychiatry. Jul-Aug 2015;23(4):245-262.

19. Hacker LE, Park JM, Timpano KR, et al. Hoarding in Children With ADHD [published online ahead of print August 2012]. J Atten Disord. 2012. doi: 10.1177/1087054712455845.

20. Anholt GE, Cath DC, Oppen P, et al. Autism and ADHD Symptoms in Patients with OCD: Are They Associated with Specific OC Symptom Dimensions or OC Symptom Severity? Journal of Autism and Developmental Disorders. 2009;40(5):580-589. 
21. Hartl T, Duffany S, Allen G, Steketee G, Frost R. Relationships among compulsive hoarding, trauma, and attention-deficit/hyperactivity disorder. Behaviour Research and Therapy. 2005;43(2):269-276.

22. Grisham J, Brown T, Savage C, Steketee G, Barlow D. Neuropsychological impairment associated with compulsive hoarding. Behaviour Research and Therapy. 2007;45(7):14711483.

23. Fullana MA, Vilagut G, Mataix-Cols D, et al. Is ADHD in childhood associated with lifetime hoarding symptoms? An epidemiological study. Depress Anxiety. Aug 2013;30(8):741-748.

24. Tolin DF. Understanding and treating hoarding: A biopsychosocial perspective. Journal of Clinical Psychology. 2011;67(5):517-526.

25. Anholt GE, Cath DC, van Oppen P, et al. Autism and ADHD symptoms in patients with OCD: are they associated with specific OC symptom dimensions or OC symptom severity? Journal of autism and developmental disorders. May 2010;40(5):580-589.

26. Hartl TL, Duffany SR, Allen GJ, Steketee G, Frost RO. Relationships among compulsive hoarding, trauma, and attention-deficit/hyperactivity disorder. Behaviour research and therapy. Feb 2005;43(2):269-276.

27. Grisham JR, Norberg MM, Williams AD, Certoma SP, Kadib R. Categorization and cognitive deficits in compulsive hoarding. Behaviour Research and Therapy. 2010;48(9):866-872.

28. Grisham JR, Norberg MM. Compulsive hoarding: current controversies and new directions. Dialogues in clinical neuroscience. 2010;12(2):233-240.

29. Pallanti S, Grassi G, Sarrecchia ED, Cantisani A, Pellegrini M. Obsessive-compulsive disorder comorbidity: clinical assessment and therapeutic implications. Front Psychiatry. 2011;2:70.

30. Crosbie J, Arnold P, Paterson A, et al. Response inhibition and ADHD traits: correlates and heritability in a community sample. J Abnorm Child Psychol. Apr 2013;41(3):497-507.

31. Achenbach T. Manual for the Child Behavior Checklist/4-18 and 1191 Profile. Burlington, VT: University of Vermont Department of Psychiatry;1991.

32. Valleni-Basile LA, Garrison CZ, Jackson KL, et al. Frequency of obsessive-compulsive disorder in a community sample of young adolescents. Journal of the American Academy of Child and Adolescent Psychiatry. Jul-Aug 1994;33(6):782-791.

33. Kendall PC, Puliafico AC, Barmish AJ, Choudhury MS, Henin A, Treadwell KS. Assessing anxiety with the Child Behavior Checklist and the Teacher Report Form. J Anxiety Disord. 2007;21(8):1004-1015.

34. Grills-Taquechel AE, Fletcher JM, Vaughn SR, Denton CA, Taylor P. Anxiety and inattention as predictors of achievement in early elementary school children. Anxiety, stress, and coping. 2013;26(4):391-410.

35. Rapoport JL, Inoff-Germain G, Weissman MM, et al. Childhood obsessive-compulsive disorder in the NIMH MECA study: parent versus child identification of cases. Methods for the Epidemiology of Child and Adolescent Mental Disorders. J Anxiety Disord. Nov-Dec 2000;14(6):535-548.

36. Frank $\mathrm{H}$, Stewart E, Walther $\mathrm{M}$, et al. Hoarding behavior among young children with obsessive-compulsive disorder. J Obsessive Compuls Relat Disord. Jan 1 2014;3(1):6-11.

37. Bloch MH, Craiglow BG, Landeros-Weisenberger A, et al. Predictors of Early Adult Outcomes in Pediatric-Onset Obsessive-Compulsive Disorder. Pediatrics. 2009;124(4):1085-1093.

38. Palermo SD, Bloch MH, Craiglow B, et al. Predictors of early adulthood quality of life in children with obsessive-compulsive disorder. Social Psychiatry and Psychiatric Epidemiology. 2010;46(4):291-297.

39. Bloch MH, Bartley CA, Zipperer L, et al. Meta-analysis: hoarding symptoms associated with poor treatment outcome in obsessive-compulsive disorder. Mol Psychiatry. Sep 2014;19(9):1025-1030. 
40. Zohar AH, Felz L. Ritualistic behavior in young children.J Abnorm Child Psychol. Apr 2001;29(2):121-128.

41. Torres AR, Fontenelle LF, Ferrão YA, et al. Clinical features of obsessive-compulsive disorder with hoarding symptoms: A multicenter study. Journal of Psychiatric Research. 2012;46(6):724-732.

42. Masi G, Millepiedi S, Perugi G, et al. A Naturalistic Exploratory Study of the Impact of Demographic, Phenotypic and Comorbid Features in Pediatric Obsessive-Compulsive Disorder. Psychopathology. 2010;43(2):69-78.

43. Hall BJ, Tolin DF, Frost RO, Steketee G. An Exploration of Comorbid Symptoms and Clinical Correlates of Clinically Significant Hoarding Symptoms. Depression and Anxiety. 2013;30(1):67-76.

44. Galbaud du Fort G, Newman SC, Bland RC. Psychiatric comorbidity and treatment seeking. Sources of selection bias in the study of clinical populations. J Nerv Ment Dis. Aug 1993;181(8):467-474.

45. Storch EA, Muroff J, Lewin AB, et al. Development and Preliminary Psychometric Evaluation of the Children's Saving Inventory. Child Psychiatry \& Human Development. 2010;42(2):166182.

46. Kichuk SA, Torres AR, Fontenelle LF, et al. Symptom dimensions are associated with age of onset and clinical course of obsessive-compulsive disorder. Progress in neuropsychopharmacology \& biological psychiatry. Jul 1 2013;44:233-239.

47. Frost RO, Steketee G, Grisham J. Measurement of compulsive hoarding: saving inventoryrevised. Behav Res Ther. Oct 2004;42(10):1163-1182.

48. Tolin DF, Frost RO, Steketee G, Fitch KE. Family burden of compulsive hoarding: Results of an internet survey. Behaviour Research and Therapy. 2008;46(3):334-344.

49. Kim HJ, Steketee G, Frost RO. Hoarding by elderly people. Health \& social work. Aug 2001;26(3):176-184.

50. Tolin DF, Frost RO, Steketee G, Gray KD, Fitch KE. The economic and social burden of compulsive hoarding. Psychiatry Research. 2008;160(2):200-211. 